\title{
Rational Emotive Behavior Theraphy Approach to Overcoming Traumatized Child Victims of Domestic Violence
}

\author{
Afni Rizkah Pulungan \\ ${ }^{1}$ Universitas Negeri Padang
}

\begin{tabular}{l}
\hline Article Info \\
\hline Article history: \\
Received Dec $13^{\text {th }}, 2019$ \\
Revised Jan $8^{\text {th }}, 2020$ \\
Accepted Feb $12^{\text {th }}, 2020$ \\
\hline
\end{tabular}

\section{Keyword:}

Trauma

Korban KDRT

Pendekatan REBT

\begin{abstract}
Trauma is a psychological symptom that causes a child to be frightened due to an event he has experienced that causes a child to imagine an event that makes him afraid or traumatized, so there is need for help to overcome it. Rational Emotive Behavior Theraphy (REBT) is an approach that rationalizes irrational children's thinking to be rational. This article belongs to the type of qualitative research with a case study approach. The subject in this article is one student with criteria as a child who experiences domestic violence by his biological father who is separated from his mother. Taking the subject of this study using purposive sampling method. This study uses REBT approach techniques, data collection by interview counseling and observation. The technique guarantees the validity of the data carried out by building close relationships with subjects and informants naturally and continually making observations. Data analysis techniques were carried out by means of data reduction, data display and conclusion drawing and verification.
\end{abstract}

\section{Corresponding Author:}

Afni Rizkah Pulungan,

Email: afnirizkahp@gmail.com

\section{Pendahuluan}

Penderita trauma seringkali disebabkan oleh pengalaman masa lalu seseorang. Tidak menutup kemungkinan seseorang yang mengalami trauma terjadi sejak masa kanak-kanak. Pada umumnya seseorang yang mengalami trauma itu terjadi karena pada saat individu tersebut mengalami suatu kejadian trauma dan tidak ada yang mampu menenangkan atau mendukung penderita trauma pada saat awal kejadian, sehingga akibat peritiwa itu menjadi suatu permasalahan atau penyakit mental dalam diri individu, salah satunya adalah penderita trauma Kekerasan Dalam Rumah Tangga KDRT (Fitriani, 2018). Penulis menemukan kasus anak korban Kekerasan Dalam Rumah Tangga (KDRT) dengan inisial VV yang dilakukan oleh Ayah kandungnya sendiri di SMA kota Padang.

Kasus Kekerasan Dalam Rumah Tangga (KDRT) di Indonesia tidak lagi menjadi permasalahan sekelompok masyarakat, tetapi juga menjadi permasalahan yang krusial di seluruh lapisan masyarakat, baik di pedesaan maupun di perkotaan. Bahkan, terjadi peningkatan jumlah kekerasan setiap tahunnya (Rafikah \& Rahmawati, 2015; Wahab, 2006). Menyikapi permasalahan ini, pemerintah telah melakukan berbagai upaya pengentasan dan pencegahan kekerasan dalam rumah tangga, salah satunya dengan membuat Undangundang No. 23 Tahun 2004 tentang penghapusan Kekerasan Dalam Rumah Tangga (KDRT) sebagai dasar hukum yang mengatur masalah KDRT di Indonesia. Namun demikian, jumlah kasus KDRT di Indonesia masih mengalami peningkatan pasca dikeluarkannya undang-undang tersebut. Hal ini berarti pelaksanaan 
undang-undang No. 23 Tahun 2004 belum berhasil menekan dan menyelesaikan masalah KDRT di Indonesia. Kekerasan Dalam Rumah Tangga (KDRT) dapat diartikan sebagai tindakan kekerasan yang dilakukan oleh seorang pengasuh, orangtua, atau pasangan yang berakibat timbulnya kesengsaraan atau penderitaan secara fisik, seksual, psikologis, dan/atau penelantaran rumah tangga termasuk ancaman untuk melakukan perbuatan, pemaksaan, atau perampasan kemerdekaan secara melawan hukum dalam lingkup rumah tangga (Mudjiati, 2008). KDRT secara umum banyak terjadi di daerah perkotaan yang umumnya kasusnya belum dilaporkan kepada kepolisian maupun ke pusat layanan kesehatan karena cendrung kasus bersifat privasi (Field, Onah, Heyningen, \& Honikman, 2018).

Kekerasan Dalam Rumah Tangga (KDRT) menjadi isu penting dalam beberapa dekade terakhir ini. Menurut laporan World Health Organization (WHO) antara 40 hingga 70 persen perempuan di dunia meninggal akibat kekerasan yang terjadi dalam rumah tangga. (Rafikah \&Rahmawati, 2015). Dalam lingkup kehidupan keluarga bukan hanya istri yang menjadi korban tetapi kasus kekerasan juga terjadi pada anak, juga merabah pada sektor pendidikan formal mulai tingkat dasar sampai perguruan tinggi. Padahal intitusi inilah yang paling diharapkan menjadi garda terdepan, penanaman nilai moral, karakter dan agama dalam kehidupan 2013 (Ramadani \& Yuliani, 2017).

Adapun tujuan dari penulis disini perlunya memberikan bantuan kepada klien yang memiliki permasalahan baik dari aspek psikologis maupun aspek kognitifnya akibat korban KDRT dari Ayah kandungnya. "Bagaimana perubahan aspek psikologi dan aspek kognitif anak korban KDRT? Seseorang yang mengalami trauma dapat diberikan bantuan melalui layanan dan pendekatan sesuai dengan tingkatan dan permasalahan yang dialami individu itu sendiri. Salah satu pendekatan yang dapat digunakan adalah pendekatan Rational Emotif Behaviour Theraphy (REBT). Pendekatan ini dapat diberikan untuk mengubah pola pemikiran individu yang irasioal karena suatu peristiwa yang membuatnya mengalami sakit mental atau psikinya mengalami gangguan, menjadi pemikiran yang rasional. Hal tersebut dapat membantu klien dalam mengentaskan permasalahan klien yang megalami suatu kejadian trauma akibat KDRT oleh Ayah kandungnya sendiri sejak ia SMP kelas 1 sehingga perlunya ada bantuan penanganan menggunakan REBT ini (Fitriani, 2018).

Berdasarkan penjelasan di atas, dapat disimpulkan bahwa dampak anak korban yang berinisial VV KDRT yaitu trauma karena anak menjadi korban KDRT oleh ayah kandungnya sendiri. Anak sebagai individu yang menjadi korban KDRT sangat membutuhkan penanganan untuk mengatasi traumanya dengan menggunakan pendekatan Rational Emotive BehaviorTheraphy (REBT) melalui pendekatan REBT diharapkan anak dapat membantu mengatasi rasa traumanya akibat KDRT dari ayahnya (Afdal et al., 2019).

\section{Kajian Teori \\ Pengertian Rational Emotive Behavior Theraphy (REBT)}

Rational Emotive Behavior Theraphy (REBT) merupakan pendekatan yang lebih menekankan kepada bagaimana pentingnya peran pikiran pada tingkah laku. Pendekatan ini lebih melihat bahwa individu merupakan bagian yang didominasi oleh sistem berfikir dan sistem perasaan yang berkaitan dengan sistem psikis didalam dirinya.(Windy, 2004).

\section{Tujuan Rational Emotive Behavior Theraphy (REBT)}

Tujuan yang terpenting dalam konseling yang memanfaatkan pendekatan REBT ialah membantu individu dalam menyadari bahwa mereka dapat hidup lebih rasional dan lebih baik lagi dengan pemikiran yang rasional. Adapun beberapa tujuan dalam menggunakan pendekatan REBT yaitu membantu klien menumbuhkan minat. Membantu klien menumbuhkan minat sosial. Membantu klien dalam menumbuhkan pengarahan diri. Menumbuhkan sikap toleransi dalam diri klien. Membantu klien dalam memiliki penerimaan diri. Membnatu klien dalam menerima sesuatu hal yang tidak sesuai dengan keinginannnya. Membantu klien dalam menerima setiap kejaidan bahwa apapun yang akan dijalani akan memiliki berbagai resiko (Windy, 2004).

Adapun cara dalam mengatasinya melalui pendekatan REBT yaitu: Berperan aktif dan diretif, yaitu konselor dapat mengambil peran lebih banyak untuk memberikan penjelasan untuk klien terutama pada awal konseling. Konselor dapat mengkonfrontasikan pikiran irasional yang dikemukakan klien. Konselor dapat menggunakan berbagai teknik yang ada untuk menstimulus klien dalam berfikir. Konselor dapat mengembalikan terus menerus berhubungan dengan pemikiran-pemikiran irasional.Konselor dapat membnatu 
klien dalam mengajak klien untuk mengatasi pemikiran-pemikiran yang irasional menajdi rasonal dan mewujudkannya dalam perilaku yang dimilikinya.

\section{Metode}

Artikel ini termasuk pendekatan kualitatif dengan jenis studi kasus dengan menggunakan pendekatan teknik Rational Emotive Behavior Tehraphy (REBT) yang terdiri dari aspek psikologis dan kognitif. Penelitian studi kasus adalah penelitian yang bertujuan mengembangkan analisis secara mendalam dari sebuah kasus tunggal atau kasus jamak (Creswell, 2007). Studi kasus mengutamakan eksplorasi dari suatu sistem yang saling terkait satu sama lain dalam beberapa hal satu kasus secara mendetail, disertai dengan penggalian data secara mendalam yang melibatkan dari beberbagai lini yang kaya akan konteks (Herdiansyah, 2015). Penelitian dalam kualitatif bertindak sebagai instrumen penelitian yang memberikan gambaran tentang kondisi secara faktual dan sistematis fenomena yang dimiliki (Moleong, 2007).

Teknik pengambilan data melalui wawancara dan observasi. Responden dalam penelitian merupakan seorang peserta didik yang sedang bersekolah di SMA di Kota Padang dan inisial VV sebagai anak korban KDRT dan juga sebagai informan dalam penelitian ini dengan teknik snowball, dengan maksud mendapatkan data yang pada mulanya sedikit menjadi semakin lama semakin besar dari keterangan informan (Miles \& Huberman, 1992). Informan tambahan yaitu teman sekelas dari VV yang berinisial ILM dan NRL. Adapun analisis data dengan mengikuti reduksi data, penyajian data dan kesimpulan.

\section{Hasil dan Pembahasan Temuan Penelitian}

Temuan penelitian ini mendeskripsikan tentang aspek-aspek kondisi trauma individu. Artikel ini mengatasi trauma anak korban KDRT dengan menggunakan pendekatan REBT yang mengalami KDRT , yang terdiri dari dari dua aspek, (1) Behavioral dan, (2) aspek kognitif. Tujuan penelitian ini untuk melihat perubahan aspek behavioral dan aspek kognitif dari VV sebagai anak korban KDRT oleh ayah kandungnya.

VV merupakan anak sulung dari dua orang bersaudara. Berdomisili di Padang. Ayahnya bekerja di perusahaan swasta dan Ibu seorang ibu rumah tangga. VV mengalami KDRT dari Ayahnya sejak VV duduk di bangku SMP kelas 1. VV di pukul dan di tendang. Kekerasan fisik ini sering terjadi ketika ayahnya pulang bekerja dan sejak ibunya pergi meninggalkan mereka dan bekerja di Malaysia. Ibu VV juga sering berkelahi dengan Ayahnya karena masalah ekonomi dan setelah tinggal di Padang ibunya menceraikan Ayahnya, tetapi Ayahnya tidak mau menandatangani surat perceraian itu dan lalu Ibunya pergi ke Malaysia. Adapaun cara konselor dengan melakukan konfrontasi saat VV konseling Individu atas pemikiran irasionalnya dan untuk mengubah tingkah lakunya, dan setelah tiga pertemuan terlihat perubahan VV baik secara psikologis maupun kognitif.

Berdasarkan temuan dari informan tambahan yaitu dengan inisial ILM dan NRL, yang diperoleh dari ILM sebagai informan tambahan bahwa sikap VV di kelas sangat kasar dalam berbicara dan bersikap seperti lelaki seperti memukul meja, berteriak kencang dan lain sebagainya. Sedang yang diperoleh dari NRL sebagai informan kedua yaitu VV kasar berbicara di dalam kelas dan suka membentak.

Adapun temuan pertama, yang diperoleh dari perubahan aspek behavioral VV mulai menerima secara perlahan saran yang diberikan. Pada pertemuan kedua, VV sudah mulai merubah sikapnya yang berbicara kasar atau suka berteriak kepada temannya. Pada pertemuan ketiga, tingkah lakunya mulai berubah dan bersikap lebih lembut kepada temannya. Pertemuan pertama, dari perubahan aspek kognitif yaitu pada pertemuan pertama VV bercerita tidak semangat belajar dan berpikir tidak ada gunanya belajar, pada pertemuan pertama VV mulai memahami perlunya belajar untuk masa depan. Pertemuan kedua, VV mulai semangat belajar dan merubah cara pikirkan bahwa perlunya ia membanggakan kedua orangtuanya. Pada pertemuan ketiga, VV mulai mempersiapkan targetnya memperoleh bidikmisi untuk melanjutkan ke perguruan tinggi, terlihat VV semakin semangat dan percaya diri akan meraih kesuksesan dimasa depannya.

Perubahan Aspek Behavioral 
Awalnya VV mengalami KDRT oleh Ayah kandungnya sendiri sejak ia SMP, setelah ibunya pergi meninggalkan mereka. Ayahnya juga sering bertengkar dengan ibunya sejak ia kelas 6 SD. Dahulu keluarga mereka sangat hangat dan tentram. Tetapi sejak pindak ke Padang, ibu dan Ayahnya sering bertengkar dari cerita korban masalah ekonomi. Dan Ayahnya juga kasar terhadap ibunya, setelah SMP ibunya tidak tahan dan ingin bercerai dikarenakan ayahnya tidak mau menandatangani dan ibunya pergi meninggalkan mereka dan pergi ke malaysia. Ibunya mengajak VV ikut pergi, tetapi VV memikirkan adiknya yang laki-laki, kasian jika ditinggalkan kata VV. Sejak saat Ibunya pergi kekerasan kerap diterima oleh VV dari Ayahnya, terutama ketika Ayahnya pulang bekerja, Ayahnya sering marah (berkata kasar) dan melampiaskan kekesalannya dengan memukul VV korban tersebut. Sering juga VV melakukan perlawanan karena tidak terima dipukuli terus-menerus oleh Ayahnya.

Temuan dari hasil observasi yang peneliti lakukan di sekolah saat pembelajaran dan diluar jam pembelajaran penulis mewawancarai informan teman sekelasnya dengan inisial ILM dan NRL dan penulis mendapatkan hasil wawancara bahwa VV adalah anak yang suka berbicara kasar di kelas kepada temantemannya dan terlihat tidak takut dengan siapa pun. Dia secara emosional baik dalam bergaul sedikit kasar dan suaranya besar kemudian terkadang membentak dalam berbicara atau suka memukul meja. Beberapa temannya bercerita kepada penulis bahwa mereka sering sakit hati atas ucapannya dan tingkah lakunya yang mereka nilai terlalu kasar.

Dan hasil wawancara dengan VV dia mengakui dalam berbicara sudah terbiasa seperti itu, dan secara psikologis ia sering merasa tidak kuat akan KDRT tersebut, tetapi ia bertahan karena memikirkan adiknya yang masih kecil. Ia berkata sangat sedih dengan masalah yang ia alami, karena dahulu keluarga mereka harmonis dan ia sangat merindukan kenangan mereka dahulu ketika ia masih kecil. Saya juga iri Bu melihat orang yang lengkap dengan orang tua nya yang sedang bermain dan bercanda tawa dengan ibu dan ayahnya, saya sering nangis dan merindukan keluarga saya yang seperti dulu. Hal yang baik dari VV selama mendapatkan kekerasan fisik, dalam hal akademik ketika ia SMP ia selalu mendapatkan juara 1 dalam kelas.

Hasil pertemuan pertama setelah dilakukan teknik REBT dalam konseling individu yaitu wawancara konseling, VV menceritakan permasalahannya, kemudian konselor lebih banyak aktif mengkonfrontasikan pemikiran irasionalnya. Terlihat VV mulai meluapkan perasaannya dengan menangis dan awalnya ia juga masih berat tetapi terlihat perubahannya mulai ia terima secara perlahan karena tingkah lakunya mulai berubah.

Pada saat pertemuan kedua perubahan perlakuan VV dan penulis juga sebelumnya sudah mewawancarai teman satu kelasnya untuk mencari informasi perubahan perilaku VV yang mereka katakan kasar. Setelah penulis telusuri VV mulai merubah sikapnya. Sedangkan pada saat wawancara konseling VV sudah mulai tersenyum dan terlihat secara psikologis ia mulai ikhlas atas permasalahan yang dialaminya, terlihat dari katakatanya "VV sudah mulai semangat Bu belajar lagi, karna VV mau membahagiakan Ibu dan Ayah". Hal tersebut akan berdampak pada tingkah lakunya yang tidak semangat belajar dan sikap yang terlihat seenaknya kepada teman sekelasnya.

Pada saat pertemuan ketiga VV sudah mulai perlahan menghilangkan rasa sedih akibat permasalahan yang ia alami, dapat dilihat dari kata-katanya setelah penulis mengatakan "kamu diberikan Allah cobaan karena kamu sanggup dan kuat, dan banyak orang diluar sana tidak pernah merasakan kasih sayang kedua orang tuanya bahwa banyak mereka tidak mengenal kemudian banyak yang tidak bisa sekolah." Kemudian pada wawancara konseling ini "ia Bu VV mulai menyadari harusnya VV bersyukur dan menghilangkan sedih agar bisa semangat belajar meraih masa depan." Terlihat bahwa VV mulai sedikit dan secara perlahan melupakan pengalaman yang membuatkan trauma dan sedih. Kemudian tingkah lakunya yang suka memukul meja atau sedikit tomboy sudah bisa mulai dirubahnya. VV mulai menyadari sikapnya yang kasar tidak pantas ia lakukan kepada temannya.

\section{Perubahan Aspek Kognitif}

Temuan dampak kognitifnya, VV yang selalu menerima kekerasan oleh Ayahnya, seperti yang dikemukakan oleh ahli bahwa individu memiliki karakteristik yang mempunyai pikiran irasional yang berasal dari proses belajar yang ia dapatkan dari orangtuanya maupun lingkungannya. Albert Ellis juga mengemukakan bahwa ketidakbahgiaan seseorang merupakan salah satu hasil dari peristiwa ekternal yang tidak didapat dikontrol didalam diri individu itu sendiri. Tidak hanya dalam hal itu, Ellis juga mengemukakan bahwa masa lalu dapat menentukan tingkah laku saat ini dan tidak bisa diubah. Seperti yang dikatakan VV 
saat wawancara konseling "Kadang VV berpikir Bu untuk tidak mau belajar lagi, karena rasanya kalau juara pun tidak ada yang bangga sama VV kecuali Ibu, VV rasanya tidak semangat lagi dan rindu akan keluarga utuh seperti dulu yang sering tertawa bersama."

"VV benci sekali dengan Ayah yang selalu berkata kasar dan suka melakukan kekerasan fisik terhadap saya $\mathrm{Bu}$," rasanya VV gk sanggup mau hidup terus begini sehingga kadang VV melakukan perlawanan kepada ayah karna VV kesal dan tidak pikir panjang lagi untuk membalas, VV terkadang trauma kalau teringat Ayah pulang kerja sering berkata kasar dan main pukul saja Bu padahal VV tidak ada salah". VV juga sering merasa putus asa dan takut akan masa depannya karena tidak semangat lagi untuk meraih kesuksesan itu "saya sering berpikir mau sukses juga untuk apa". Tetapi Bu terkadang Ibu saya menelepon memberi semangat dalam belajar sehingga saya tetap bertahan hingga saat ini.

Teknik yang digunakan yaitu teknik REBT dengan merasionalkan kembali pemikiran VV ketika wawancara konseling agar ia semangat dan kembali berpikir rasional lagi untuk masa depannya, kemudian tetap berbakti kepada kedua orang tuanya sehingga rasa traumanya akan berkurang secara perlahan. Pendekatan ini digunakan ketika konseling individu atau wawancara konseling agar terlihat perubahan pada informan tersebut.

Hasil pertemuan pertama VV terlihat mulai merubah cara pikirnya yang tadinya selalu ia berpikir untuk membalas, setelah dilakukan teknik ia mulai sadar sebaiknya ia tidak membalas. Pertemuan kedua VV terlihat mulai merubah pikirannya juga untuk kembali semangat belajar dan meraih kesuksesan dan ia ingin kuliah. "VV ingin kuliah $\mathrm{Bu}$ mau usaha biar bidik misi untuk keperguruan tinggi". Pertemuan ketiga VV terlihat mulai kembali semangat dan pemikiran untuk tidak sukses mulai diubahnya dan mulai terlihat hasilnya ia semakin percaya diri untuk sukses dan mendapatkan bidik misi. Pada proses konseling terakhir VV sudah terlihat optimis ketika wawancara konseling untuk meraih bidikmisi untuk kuliah di perguruan tinggi.

\section{Kesimpulan}

Hasil artikel terungkap bahwa kondisi VV dari segi (1) aspek behavioral VV sangat trauma akan kejadian yang ia alami akibat KDRT yang ia terima oleh Ayahnya, (2) VV merasa putus asa dan tidak semangat meraih kesuksesan untuk masa depannya. Dengan digunakan pendekatan REBT ini, VV sudah mulai bisa mengurangi rasa traumanya dan pemikirannya yang irasional bisa di rasionalkan kembali.

\section{Ucapan Terima Kasih}

Peneliti mengucapkan terima kasih atas bantuan Allah Swt karena memberikan kesehatan dan kesempatan untuk melakukan penelitian ini, terima kasih juga kepada Bapak Amriman M, S.Pd., M.M selaku kepala sekolah yang memberikan kesempatan untuk meneliti di tempat beliau. Terima kasih juga penulis ucapkan kepada Ibu Narmiati S.Pd., Kons selaku guru BK di sekolah tersebut. Selanjutnya teman-teman sejawat yang senantiasa memberikan kritik dan sarannya dalam proses penelitian ini. Semoga penelitian ini bisa memberikan manfaat bagi banyak orang terkhusus di lingkup BK.

\section{References}

Afdal, A., Arnaldy, A., Nirwana, H., Alizamar, A., Zikra, Z., Ilyas, A., \& Fikri, M. (2019). Increasing life satisfaction of domestic violence victims through the role of supporting group therapy on social media. Advances in Social Science, Education and Humanities Research, Volume 372, 372(ICoET), 139-144.

Creswell, J. W. (2007). Research Design. (Diana E. Axelsen, Ed.) (Second Edi). London and New delhi: Sage Publication.

Field, S., Onah, M., Heyningen, T. V, \& Honikman, S. (2018). Domestic and intimate partner violence among pregnant women in a low resource setting in South Africa: A facility-based, mixed methods study. BMC Women's Health, 18(1), 1-13. https://doi.org/10.1186/s12905-018-0612-2

Fitriani, D. (2018). Peran Konselor Terhadap Klien Yang Mengalami Trauma Melalui Teknik Rational Emotif Behaviour Theraphy ( REBT ), 3, 63-67.

Herdiansyah, H. (2015). Metodologi Penelitian Kualitatif untuk Ilmu Psikologi. (Rosidah, Ed.) (1st ed.). Jakarta: Salemba Humanika. 
Miles, M. ., \& Huberman, A. . (1992). Analisis Data Kualitatif Buku Sumber Tentang Metode-Metode Baru. Jakarta: UI Press.

Moleong, L. . (2007). Metodologi Penelitian Kualitatif(23rd ed.). Bandung: PT. Remaja Rosdakarya.

Mudjiati. (2008). Undang-undang No. 23 tahun 2004 tentang Penghapusan Kekerasan dalam Rumah Tangga (UU-PKDRT).

Rafikah, \& Rahmawati. (2015). Peranan Pusat Pelayanan Terpadu Pemberdayaan Perempuan dan Anka (P2TP2A) Dalam Menghapuskan Kekerasan dalam Rumah Tangga (KDRT) di Kota Bukittinggi. Journal of Islamic \& Social Studies, 1(2), 173-186.

Ramadani, M., \& Yuliani, F. (2017). Kekerasan Dalam Rumah Tangga (Kdrt) Sebagai Salah Satu Isu Kesehatan Masyarakat Secara Global. Jurnal Kesehatan Masyarakat Andalas, 9(2), 80. https://doi.org/10.24893/jkma.9.2.80-87.2015

Windy Dryden (2004). Rational Emotive Behavior Therapy: Theoretical Development Advancing Theory in Therapy. Routledge

Wahab, R. (2006). Kekerasan dalam Rumah Tangga: Persfektif Psikologis dan Edukatif. UNISIA, $X X i X / I I I(B u d a y a$ dan Kekerasan), 247-256. 